\title{
INDICADORES EDUCACIONAIS DE MATRÍCULAS DE ALUNOS COM DEFICIÊNCIA NO BRASIL (1974-2014)
}

ANDRESSA SANTOS REBELO MÔNICA DE CARVALHO MAGALHÃES KASSAR

\section{RESUMO}

O uso de dados estatísticos foi por algum tempo preterido por parte da literatura educacional. Ciente desse movimento, este trabalho propõe-se a analisar a utilização de indicadores educacionais para conhecimento da realidade desse campo. São apresentados $e$ analisados indicadores educacionais referentes a matrículas de alunos da Educação Especial no Brasil entre 1974 e 2014. Os dados são estudados sob uma perspectiva crítica, em interlocução com a literatura da área. O texto questiona a forma como tais informações têm sido usadas, em especial pelo Governo Federal, como demonstrativos dos avanços da política de inclusão escolar. Conclui-se que tais indicadores necessitam ser articulados a uma leitura que considere os impactos das ações dos governos, além de ter como interlocução dados e pesquisas que propiciem diferentes leituras.

PALAVRAS-CHAVE EDUCAÇÃO ESPECIAL • INDICADORES EDUCACIONAIS - POLÍTICAS EDUCACIONAIS - INDICADORES SOCIAIS. 


\title{
INDICADORES EDUCACIONALES DE MATRÍCULAS DE ESTUDIANTES CON DISCAPACIDAD EN BRASIL (1974-2014)
}

RESUMEN

El uso de los datos estadísticos fue por algún tiempo desconsiderado por parte de la literatura educacional. Consciente de ese movimiento, este trabajo se propone a analizar la utilización de indicadores educacionales para el conocimiento de la realidad de este campo. Son presentados y analizados los indicadores educacionales de matrículas de alumnos de Educación Especial en Brasil entre los años 1974 y 2014. Se estudian los datos desde una perspectiva crítica, manteniendo interlocución con la literatura del área. El texto cuestiona la forma como tales informaciones han sido utilizadas, especialmente por el Gobierno Federal, como muestras de los avances de la politica de inclusión escolar. Se concluye que hay que articular tales indicadores a una lectura que considere los impactos de las acciones de los gobiernos y, además, que tengan interlocución con datos e investigaciones académicas para que sean posibles distintas miradas.

PALABRAS CLAVE EDUCACIÓN ESPECIAL • INDICADORES EDUCACIONALES • POLÍTICAS EDUCACIONALES • INDICADORES SOCIALES.

\section{EDUCATION INDICATORS RELATED TO THE ENROLLMENT OF PUPILS WITH DISABILITIES IN BRAZIL (1974-2014)}

\begin{abstract}
The use of statistical data has been underestimated by part of educational literature for some time. Being aware of this, the present paper aims to discuss the use of educational indicators to understand the situation of this field. The text presents and analyzes education indicators regarding the enrollment of Special Needs pupils in Brazil between 1974 and 2014. The data are analyzed from a critical perspective, in connection with the area literature. The study challenges the way in which the Federal Government has been using such data, in order to demonstrate advances in school inclusion policy. The conclusion is that such indicators need to be developed from a perspective that considers the impacts of government action, and to be connected with other data and academic research.
\end{abstract}

KEYWORDS SPECIAL EDUCATION • EDUCATIONAL INDICATORS • EDUCATIONAL POLICIES $\cdot$ SOCIAL INDICATORS. 


\section{INTRODUÇÃO}

Até os anos 1970, julgou-se que a pesquisa em avaliação prescindia de tomada de posição, de valores, que era objetiva, técnica e distante da política (ROSEMBERG, 2013). Isso se deve à existência de uma dualidade entre teoria e empiria, tradição na pesquisa em educação no país, influenciada pela pesquisa social americana e europeia. Ambas as formas de pensamento impactaram as pesquisas no Brasil, mas não foram, segundo a avaliação de Goergen (1985, p. 3-4), objeto de estudos epistemológicos mais sistemáticos e continuados:

Talvez seja esta uma das razões da existência paralela e isolada das duas formas de investigação: uma, voltada para os textos, aspectos históricos, fundamentos, de caráter teórico-filosófico e que não dá muita atenção aos fatos reais; outra, dedicada às pesquisas empíricas, obcecada, muitas vezes, pelo afã de juntar dados e desatenta aos elementos explicativos que se escondem por detrás dos fatos. 
Posicionamentos exclusivos como esse foram amplamente criticados no campo da pesquisa em educação (FRANCO; GOLDBERG, 1976; FRANCO, 1984). Também marcou presença a crítica da até então ausência de pesquisas com o objetivo de avaliar programas ou projetos educacionais (GOUVEIA, 1976). A partir dos anos 1980, a pesquisa em educação sofreu uma inflexão, vinculada ao esforço de se conjugar teoria-empiria. Assim, embora sujeita a críticas, a pesquisa educacional tem procurado avançar nesse sentido (GAMBOA, 1994).

Desse histórico, tem origem a defesa de que a pesquisa em políticas públicas deve assumir a não neutralidade, independentemente dos procedimentos metodológicos que use. Ao se adotar uma perspectiva política, a pesquisa avaliativa estabelece e declara suas lealdades em relação à sua função, seus objetivos, métodos, procedimentos, ética e divulgação de resultados (ROSEMBERG, 2013).

Cabe revelar algumas características das tradições da pesquisa em política pública. Conforme Souza (2007), na Europa, a área de política pública surgiu no século XX como um desdobramento dos trabalhos baseados em teorias explicativas sobre o papel do Estado e de uma das mais importantes instituições do Estado, o governo, produtor por excelência de políticas públicas. Nos Estados Unidos, a área ingressou no mundo acadêmico sem estabelecer relações com as bases teóricas sobre o papel do Estado, passando diretamente para a ênfase nos estudos sobre a ação dos governos.

Rosemberg (2001) faz a apreciação de que, na avaliação de políticas públicas, o conhecimento acadêmico deve se desvencilhar da visão economicista predominante em pesquisas sociais, carregada da aura de neutralidade científica, inquestionável, já que objetiva e orienta opções absolutas de prioridades e estratégias em políticas públicas. Sob essa ótica, decisões políticas são vestidas do qualificativo de 'decisão técnica' competente, diminuindo o poder dos demais atores sociais. Esse posicionamento pretensamente objetivo/ imparcial vem sustentando um olhar para a política educacional, de modo a fundamentar procedimentos de avaliação e de responsabilização docente (SHIROMA; EVANGELISTA, 2011; VIDAL; VIEIRA, 2011). Tais ações estão fortemente 
embasadas em índices divulgados publicamente, o que impacta a compreensão da realidade educacional (BROOKE, 2013). Ainda em relação ao uso de dados, Jannuzzi (2014a) chama a atenção para o fato de que, desde a implantação de um programa governamental, as demandas por informação e conhecimento têm se voltado à avaliação de seus resultados e impactos.

Se, por um lado, esses números e índices têm sido empregados para justificar ações e programas por diferentes governos, por outro, a pesquisa em educação ainda tem se utilizado pouco de dados quantitativos. Por esses e outros argumentos, pesquisas acadêmicas que abordem a metodologia adotada pelas avaliações oficiais ou que usem os dados disponíveis colaboram para que as universidades adquiram independência em relação ao vasto material que circula como verdade (FREITAS, 2013). A apropriação das estatísticas públicas pela comunidade acadêmica, portanto, é estratégica. Na educação propriamente, esse movimento se faz indispensável, tendo em vista a amplitude das políticas nesse setor, que atingem grande parcela da população, principalmente a partir da expansão da educação básica no Brasil no decorrer do século XX.

Na primeira metade do século XX, Lourenço Filho (1947, p. 70) já ressaltava a relevância das estatísticas escolares para atender à realidade educacional. Entendia que a despreocupação com os problemas do ensino primário, até essa época, "como obra nacional", devia-se, na maior parte, à falta de levantamentos estatísticos periódicos que viessem a atestar o andamento 'excessivamente vagaroso' do desenvolvimento geral dos sistemas escolares estaduais.

Em relação ao uso da estatística na pesquisa em Educação, Sass (2012, p. 131) observa, na atualidade, reações diferentes:

As reações divergentes suscitadas pelas ciências que oscilam entre a desconfiança absoluta e a fé cega, compreensiveis de se manifestarem pelo senso comum e preocupantes à medida que grassam em meios acadêmicos, adquirem expressões singulares quando referidas às ciências particulares, como é o caso da Estatística. Na 
educação é frequente a crítica, muitas vezes proceden-

te, de que as estatísticas invadem a educação, ocultando

os problemas educacionais reais, na mesma proporção

que educadores e políticos clamam por elas, em outras circunstâncias, sob o argumento da falta de informações consistentes que orientem as proposições e programas educacionais.

Amplamente utilizada no início das pesquisas educacionais, a metodologia quantitativa se fazia presente em centros de pesquisa (LOURENÇO FILHO, 1964; GATTI, 2002). Passou a ser desacreditada a partir dos anos 1980 na pesquisa em Educação, sob o argumento de se tratar de um método sociológico positivista (SANTOS FILHO; GAMBOA, 2009). Se, por um lado, essa mudança de posição permitiu um grande desenvolvimento das metodologias qualitativas e o reconhecimento de sua legitimidade, por outro, ajudou a corroborar a retirada da Estatística da pesquisa em Educação (FERRARO, 2012), apesar do trabalho de recuperação desses estudos (FERRARO, 1979; GATTI, 1982) desde então.

O Brasil possui, atualmente, um conjunto notável de dados. Embora a sua coleta seja, a princípio, direcionada ao que o poder público pretende avaliar como resultado de determinada ação e existam problemas na metodologia do processo e no modo pelo qual são coligidos (JANNUZZI, 2009; PEREIRA; MAZZON; ROSENBERG, 1998; SASS, 2013), as informações podem ser examinadas pela academia como elementos para a avaliação de políticas públicas. Dentre esse conjunto de dados, há os obtidos através do Censo Escolar da Educação Básica, que fornecem elementos para a compreensão de aspectos da materialização das ações governamentais no campo da educação. Dentre os dados educacionais, estão os referentes a uma população que tem sido identificada como alunos da 'Educação Especial'. Este estudo enfoca, justamente, indicadores educacionais referentes às matrículas desses alunos no Brasil de 1974, data do primeiro levantamento dedicado à identificação de alunos "excepcionais" (termo utilizado à época), até 2014, ano em que se encontram os dados mais recentes sobre essa população ${ }^{1}$, com o propósito de analisar a 
utilização de indicadores educacionais para o conhecimento da realidade educacional.

Procurou-se examinar as características das políticas públicas de educação implantadas no período, destinadas a esse grupo, e a produção acadêmica relativa ao campo de investigação.

A pesquisa recorreu aos dados organizados pelo Ministério da Educação e Cultura (MEC) nos anos 1970, aos levantamentos estatísticos empreendidos pelo Instituto Nacional de Estudos e Pesquisas Educacionais Anísio Teixeira (Inep) e aos microdados obtidos pelo Censo Escolar da Educação Básica (MEC/Inep). Para a leitura e o tratamento estatístico dos microdados, utilizou-se o software IBM (International Business Machines) SPSS Statistics.

\section{INDICADORES EDUCACIONAIS DE MATRÍCULAS DE ALUNOS DA 'EDUCAÇÃO ESPECIAL'}

Diversos organismos que produzem estatísticas, assim como entidades que coletam dados administrativos, realizam inquéritos censitários ou amostrais, reunindo informações sobre um conjunto de unidades de observação. Em geral, os microdados são organizados em bases de dados em que cada linha, ou registro, contém informações (sistematizadas pelas diversas variáveis) sobre cada unidade de observação (MARTINS; MAURITTI; COSTA, 2013). O termo 'micro' indica que os dados representam características das unidades mínimas do levantamento - por exemplo: pessoas, empresas, ônibus -, e não os dados agregados em níveis superiores - tais como: municípios, setores econômicos, frotas de transporte urbano. Dados agregados não podem ser cruzados ou reprocessados; o processo de agregação é irreversível para quem não dispõe dos dados originais (SCHRADER, 2002).

Os indicadores sociais, sob uma perspectiva programática, constituem um instrumento operacional para o monitoramento da realidade social, para fins de formulação e reformulação das políticas públicas (JANNUZZI, 2009). Pelo fato de a educação ser uma área de intervenção das políticas públicas e versar sobre a realidade social de grande parte da população, 
entende-se que todo indicador educacional seja um indicador social, pois leva à avaliação de um dos aspectos de suas condições de vida (JANNUZZI, 2005; JANNUZZI et al., 2009).

Dessa forma, toma-se por conceito de indicador social:

[...] uma medida em geral quantitativa dotada de significado social substantivo, usado para substituir, quantificar ou operacionalizar um conceito social abstrato, de interesse teórico (para pesquisa acadêmica) ou programático (para formulação de políticas). É um recurso metodológico, empiricamente referido, que informa algo sobre um aspecto da realidade social ou sobre mudanças que estão se processando na mesma. (JANNUZZI, 2009, p. 15)

Partindo desse conceito, para o estudo pretendido, delimitou-se por temática social de interesse a escolarização do grupo de alunos classificado como da "Educação Especial". Essa população vem recebendo diferentes denominações nos registros estatísticos do Governo Federal: "alunos excepcionais", nos documentos dos anos 1970; "alunos portadores de deficiências, condutas típicas e altas habilidades”, entre os anos 1980 e 1990; "pessoa portadora de necessidades especiais", no início dos anos 1990; "alunos com necessidades educacionais especiais", entre o final dos anos 1990 e o início do século XXI; e, atualmente, "aluno com deficiência, transtornos globais do desenvolvimento, altas habilidades/superdotação", seguindo orientação do documento Política Nacional de Educação Especial na Perspectiva da Educação Inclusiva (BRASIL, 2008a). Tendo em vista essas alterações, ao longo do texto, quando se faz menção a 'alunos da Educação Especial', refere-se aos alunos público-alvo da educação especial em cada momento histórico.

As dimensões operacionais de interesse (indicador social) são o atendimento escolar dessa população, segundo tipo de atendimento - escola especial, classe especial, classe regular com apoio de sala de recursos, classe regular sem apoio, salas de recursos, entre outros - e matrículas - dependência administrativa, estabelecimentos e turmas.

No período de 1974 a 2006, utilizaram-se como fonte privilegiada as sinopses estatísticas existentes; de 2007 a 
2014, os microdados do Censo Escolar (MEC/Inep), divulgados pelo Ministério da Educação. Embora o banco de microdados do Inep esteja disponível desde 1995, entre esse ano e 2006, a 'escola' era a unidade de coleta. Assim, por meio do código da escola, concedia-se acesso às matrículas, obtendo as características dos alunos de escolas específicas. A partir de 2007, a unidade de coleta passa a ser o 'aluno', derivando daí a dificuldade de um estudo incidir sobre uma série histórica que perpasse esses dois períodos.

Ressaltam-se outros aspectos que marcam a data. A partir de 2007, a política educacional proposta a essa população tem duas metas claramente definidas: sua matrícula em classes comuns do ensino regular e o oferecimento de atendimento educacional especializado em Salas de Recursos Multifuncionais, no contraturno escolar. Foram identificados, como materialização dessa política, a criação do Programa de Implantação de Salas de Recursos Multifuncionais (BRASIL, 2007a) e o direcionamento de recursos para esse fim, através da dupla matrícula de alunos da Educação Especial na escola, que recebem atendimento educacional especializado, proporcionado pelo Fundo de Manutenção e Desenvolvimento da Educação Básica e de Valorização dos Profissionais da Educação (Fundeb) (BRASIL, 2007b).

Sobre o atendimento educacional especializado oferecido em Salas de Recursos Multifuncionais, os dados passaram a ser compilados e disponibilizados apenas a partir de 2009.

O ano de 1995 é marcante para o sistema de informação estatística educacional no Brasil. Nessa data, foi reformulada a Diretoria de Informações e Estatísticas Educacionais (Seec) do Inep, até então responsável por organizar os dados censitários educacionais, e criado o Sistema Integrado de Informações Educacionais (SIEd). Até janeiro de 1995, o último Censo da Educação Básica concluído e divulgado era o de 1989. A participação em projetos internacionais para a produção de indicadores educacionais e a reestruturação do sistema de informações e estatísticas educacionais são consequências também de uma mudança da forma de fazer a política educacional. A partir de 1995, a informação deixou de ser coadjuvante para assumir um papel central como instrumento 
para a formulação e a implementação das políticas educacionais. O Plano Diretor da Reforma do Aparelho do Estado (BRASIL, 1995) atingiu o Ministério da Educação, que precisava de um sistema de informação eficaz e confiável para a avaliação adequada do sistema educacional brasileiro, a fim de tornar os dados coletados relevantes para as administrações nas instâncias escola, município e estado (ALMEIDA; WOLYNEC, 1998; DINIZ, 1999).

Essas alterações indicam a racionalização da organização do Estado, emanando decisões qualificadas como "técnicas e competentes", aspecto já abordado no início deste artigo, e sua penetração nos diferentes níveis administrativos. Sobre esse movimento, Jannuzzi (2014b, p. 12) acrescenta que o fortalecimento da agenda produtora de informação estatística e da estruturação dos sistemas de monitoramento e avaliação na administração pública conduz ao questionamento sobre o "mito da falta de racionalidade técnica", na decisão política do país, e à ausência de avaliação dentro do próprio governo.

A historicidade de um indicador é a propriedade de se dispor de séries históricas extensas e comparáveis, de modo a cotejar o valor presente com situações do passado, inferir tendências e avaliar efeitos de eventuais políticas sociais implementadas. O ideal é que as cifras passadas sejam compatíveis entre si sob o ponto de vista conceitual e com confiabilidade similar. Contudo, mesmo em situações em que isso não seja possível, as tendências passadas podem dar informações úteis para a interpretação das cifras atuais dos indicadores. Poucas vezes se dispõe de séries históricas plenamente compatíveis de indicadores para a escala geográfica ou o grupo social de interesse (JANNUZZI, 2009).

Levando em conta essas dificuldades, mas também o potencial do estudo de dados longitudinais para a pesquisa educacional (BONAMINO; OLIVEIRA, 2013), foram analisadas, nesta pesquisa, as variáveis com continuidade nesses períodos, no que diz respeito aos atendimentos educacionais especializados. Admitiram-se os limites e mesmo os riscos de recorrer a fontes de naturezas distintas.

O interesse foi o de investigar o movimento de matrículas dos alunos da Educação Especial no país, a partir do 
primeiro levantamento estatístico nacional sobre Educação Especial, publicado pelo Centro Nacional de Educação Especial (Cenesp) (BRASIL, 1975).

Durante o regime militar (1964-1985), a Secretaria Geral do Ministério da Educação e Cultura (MEC) criou um grupo-tarefa destinado a realizar a implantação do Cenesp e elaborar a sua estrutura e regimento interno (BRASIL, 1973a, 1973b), como consequência de uma preocupação já sinalizada em documentos educacionais anteriores (BRASIL, 1957, 1958, 1960). O Cenesp foi idealizado "com a finalidade de promover, em todo o território nacional, a expansão e melhoria do atendimento aos excepcionais" (BRASIL, 1973c, art. $1^{\circ}$ ). No ano de 1986, momento de redemocratização do país, foi fundada a Secretaria de Educação Especial no Ministério da Educação (BRASIL, 1986), com a extinção do Cenesp. A partir dos anos 1990, os pressupostos de integração/inclusão mostraram-se mais incisivos sobre as políticas sociais, quando se sinalizou a opção pela escola comum como lócus preferencial de atendimento educacional especializado (BRASIL, 1988, 1996, 2007a), não sem o enfrentamento e o fortalecimento das lutas empenhadas pelas instituições privadas de caráter filantrópico para que não perdessem espaço e influência entre essas políticas (BRASIL, 1988, 1996, 2007b). Em 2011, a Secretaria de Educação Especial foi extinta e a incumbência por suas ações foi repassada à Secretaria de Educação Continuada, Alfabetização, Diversidade e Inclusão (Secadi) (BRASIL, 2011a). Dentro da sua estrutura organizacional, foi implementada a Diretoria de Políticas de Educação Especial.

Com o propósito de abranger o período indicado, elaborou-se a tabela a seguir, que permite a comparação do número de matrículas na Educação Especial em classes comuns, especiais e escolas exclusivas (escolas especiais) e o número de matrículas da população em geral em classes comuns do ensino regular de 1974 a 2014: 
TABELA 1 - Distribuição do número de matrículas de alunos da Educação Especial e a relação com o número de matrículas da população em geral. Brasil, 1974 a 2014

\begin{tabular}{|c|c|c|c|c|c|c|c|c|c|}
\hline \multirow{3}{*}{ ANO } & \multicolumn{7}{|c|}{ MATRÍCULAS DA EDUCAÇÃO ESPECIAL } & \multirow{3}{*}{$\begin{array}{c}\text { MATRÍCULAS DA } \\
\text { POPULAÇÃO EM } \\
\text { GERAL } \\
\text { TOTAL (B) }\end{array}$} & \multirow{3}{*}{$\begin{array}{c}\% \\
(A: B)\end{array}$} \\
\hline & \multicolumn{2}{|c|}{ CLASSES COMUNS } & \multicolumn{2}{|c|}{$\begin{array}{l}\text { CLASSES } \\
\text { ESPECIAIS }\end{array}$} & \multicolumn{2}{|c|}{$\begin{array}{l}\text { ESCOLAS } \\
\text { EXCLUSIVAS }\end{array}$} & \multirow{2}{*}{ TOTAL (A) } & & \\
\hline & $\%$ & $\mathrm{~N}$ & $\%$ & $\mathrm{~N}$ & $\%$ & $\mathrm{~N}$ & & & \\
\hline 1974 & - & - & $38,3 \%$ & 36.986 & $33,6 \%$ & 32.399 & 96.413 & 18.573 .193 & 0,51 \\
\hline 1988 & - & - & $43,6 \%$ & 78.322 & $56,4 \%$ & 101.201 & 179.523 & 24.769 .736 & 0,72 \\
\hline 1996 & $31,1 \%$ & $90.379^{*}$ & \multicolumn{2}{|c|}{$68,9 \% * *$} & \multicolumn{2}{|c|}{$201.142^{* *}$} & 291.521 & 44.584 .650 & 0,65 \\
\hline 1998 & $13,1 \%$ & 43.923 & $24,6 \%$ & 83.201 & $62,3 \%$ & 210.202 & 337.326 & 43.928 .519 & 0,76 \\
\hline 2000 & $21,4 \%$ & 81.695 & $21,3 \%$ & 81.400 & $57,3 \%$ & 219.120 & 382.215 & 49.294 .849 & 0,77 \\
\hline 2002 & $24,8 \%$ & 110.704 & $17,4 \%$ & 78.353 & $57,8 \%$ & 259.544 & 448.601 & 54.716 .609 & 0,81 \\
\hline 2007 & $46,8 \%$ & 306.136 & $11,9 \%$ & 77.728 & $41,4 \%$ & 270.742 & 654.606 & 53.028 .928 & 1,23 \\
\hline 2008 & $54,0 \%$ & 375.775 & $10,7 \%$ & 74.481 & $35,3 \%$ & 245.443 & 695.699 & 53.232 .868 & 1,30 \\
\hline 2009 & $60,5 \%$ & 387.031 & $8,4 \%$ & 53.430 & $31,1 \%$ & 199.257 & 639.718 & 52.580 .452 & 1,21 \\
\hline 2010 & $68,9 \%$ & 484.332 & $6,6 \%$ & 46.255 & $24,5 \%$ & 172.016 & 702.603 & 51.549 .889 & 1,36 \\
\hline 2011 & $74,2 \%$ & 558.423 & $5,0 \%$ & 37.497 & $20,8 \%$ & 156.385 & 752.305 & 50.972 .619 & 1,47 \\
\hline 2012 & $75,7 \%$ & 620.777 & $3,8 \%$ & 31.168 & $20,5 \%$ & 168.488 & 820.433 & 50.545 .050 & 1,62 \\
\hline 2013 & $76,9 \%$ & 648.921 & $3,6 \%$ & 30.453 & $19,4 \%$ & 163.968 & 843.342 & 50.042 .448 & 1,68 \\
\hline 2014 & $78,8 \%$ & 698.768 & $3,0 \%$ & 27.004 & $18,2 \%$ & 161.043 & 886.815 & 49.771 .371 & 1,78 \\
\hline
\end{tabular}

Fonte: MEC (conforme indicações abaixo, respectivas referências deste artigo e notas explicativas).

a) Dados de 1974: Brasil (1975, 1984, 1985) e NEPP (1988); b) Dados de 1988: Brasil (1991a, 1991b) e NEPP (1988); c) Dados de 1996: Brasil (1997); d) Dados de 1998: Brasil (1998a, 1998b, 1998c); e) Dados de 2000 e 2002: Brasil (2000, 2002); f) Dados de 2007 a 2014: MEC/Inep/Diretoria de Estatísticas Educacionais/Censo Escolar da Educação Básica (microdados) e Brasil (2010a).

Notas: Foram encontrados os números de matrícula utilizados em documentos do Observatório do Plano Nacional de Educação que tem como fonte: MEC/Inep/Censo Escolar, 2007 a 2013. Os documentos foram elaborados por Todos pela Educação. Dados estatísticos, informes e sinopses foram publicados em anos posteriores à coleta dos dados. Por exemplo, os dados referentes a 1974 estão publicados em Brasil (1975). Os dados das matrículas gerais de 1974 e 1988 não foram localizados (da direita para esquerda, segunda coluna, segunda e terceira linhas). Assim, nessas duas células foram considerados os dados de matrículas gerais dos anos de 1973 e 1985, publicados em NEPP (1988), que tem como fonte MEC/SEEC.

*Inclui as matrículas em outros tipos de atendimento. ${ }^{* *}$ Nos dados referentes ao ano de 1996, os números de matrículas em "classes especiais" e "escolas especiais" não estão desagregados.

Elaboração própria, com base nas fontes apresentadas.

Os documentos que apresentam os dados de 1974 e 1988 não traziam anotações das matrículas de alunos em classes comuns, embora se saiba que existiam, pois havia o registro de alunos em salas de recursos e elas, em princípio, atendiam alunos matriculados em salas de aulas comuns. Esses lançamentos passaram a existir em 1996. No entanto, nesse ano, não há informações sobre o número isolado de matrículas em classes comuns (com apoio especializado), já que os dados originais não possibilitam desagregar essas matrículas dos outros tipos de atendimento (sala de recursos, oficinas pedagógicas, educação precoce, etc.). No ano de 1974, o total 
percentual de classes especiais e escolas exclusivas (escolas especiais) não corresponde a $100 \%$ (38,3\% + 33,6\% não totalizam 100\%). Do seu complemento, não se apreende o quanto correspondia apenas às matrículas em classes comuns, pois havia outras formas de atendimento. Em 1988, não se localizou o registro de matrículas em classes comuns; no ano de 1996, não foi possível desagregar os dados de classes especiais e escolas exclusivas, modalidade Educação Especial.

A partir de 1998, observa-se um aumento contínuo da proporção de matrículas de alunos da Educação Especial nas classes comuns, enquanto o número de matrículas em classes especiais e escolas exclusivas sofre oscilações até apresentar a menor proporção ao final de 2014. No ano de 2008, verificou-se inflexão do número de matrículas em espaços exclusivos e inclusivos. Até 2007, o total de matrículas em espaços 'segregados' (classes especiais + escolas exclusivas) era superior ao de alunos matriculados em classes comuns, os alunos 'incluídos' (348.470 matrículas 'exclusivas' e 306.136 matrículas 'inclusivas'), passando as matrículas em classes comuns a 54\% em 2008. Em 2014, foram contabilizadas 188.047 matrículas em espaços exclusivos e 698.768 matrículas em classes comuns. Esse número corresponde a 78,8\% do total das matrículas de alunos com deficiência na educação básica (886.815).

No geral, é interessante notar que, em 40 anos, o número de matrículas de alunos da Educação Especial aumentou nove vezes, enquanto o número de matrículas da população em geral na Educação Básica aumentou apenas 2,67 vezes. Por outro lado, a proporção das primeiras em relação ao total de matrículas na educação básica não chegou a $2 \%$ dos registros (última coluna, à direita). Cabe ainda ressaltar que o número de matrículas não designa, necessariamente, o número de alunos. Desde 2007, com a implantação do Fundeb, alunos que frequentam salas de recursos recebem dupla matrícula, como forma de incentivo às redes educacionais a aderirem à política implantada.

Ainda quanto à comparação entre o número de matrículas da Educação Especial e o total geral de matrículas, segundo os dados de 1998 a 2006, Meletti e Bueno (2010) criticam 
a pequena proporção de matrículas de Educação Especial. De acordo com os autores, tendo em conta as estimativas de incidência de pessoas com deficiência da Organização Mundial de Saúde (OMS) (10\% da população) e do Instituto Brasileiro de Geografia e Estatística (23,9\% no Censo Demográfico de 2010) (IBGE, 2010), adotadas oficialmente no Brasil, uma parcela muito pequena dessa população recebe algum tipo de escolarização no país (MELETTI; BUENO, 2013). Em todos os casos, não há como afirmar se existe subnotificação ou excesso de notificação de pessoas com deficiência, na escola e fora dela.

Além dos problemas mencionados por diferentes autores em relação à metodologia do processo de coleta, ao modo pelo qual os dados são coligidos (JANNUZZI, 2009; SASS, 2012) e às questões específicas da Educação Especial (MELETTI; BUENO, 2010, 2013), sublinha-se que o número de anotações de matrículas do público-alvo da Educação Especial é direcionado pelas mudanças conceituais na determinação dessa população, dispostas pela legislação educacional do período, algo que está distante de ser trivial ou secundário na análise dessa temática.

Como exemplos, nos anos 1970, a identificação desses alunos direcionou-se pela Lei Educacional 5.692/71, que entendia serem merecedores de "tratamento especial" na educação os alunos que apresentassem "deficiências físicas ou mentais", os que se encontrassem "em atraso significativo quanto à idade regular de matrícula" e os "superdotados", como determinava o artigo $9^{\circ}$ (BRASIL, 1971). Trabalhos acadêmicos sobre a época (PASCHOALICK, 1981; FERREIRA, 1993; KASSAR, 1994) denunciaram a transformação de alunos "atrasados" em relação à série escolar esperada em "alunos com deficiência mental educável”, por sua matrícula compulsória em classes especiais.

Nos anos 2000, o público da Educação Especial eram os alunos com necessidades educacionais especiais, alguns dos quais não tinham, necessariamente, deficiência por causa orgânica, conforme a definição da Resolução CNE/CEB n. 2/2001 (BRASIL, 2001). Posteriormente, a Política Nacional de Educação Especial na Perspectiva da Educação Inclusiva, 
divulgada no ano de 2008, restringiu essa população a "alunos com deficiência, transtornos globais do desenvolvimento e altas habilidades ou superdotação" (BRASIL, 2008a, p. 6). É interessante observar que, apesar da restrição, não houve diminuição das matrículas. Ao contrário, ocorreu um contínuo crescimento.

Além de problemas que envolvem o diagnóstico de alguns casos, como avaliam Kassar (1994), Mendes (1995), Anache (1997), entre outros autores, há ainda outras questões. Um estudo elaborado por Dias (2014) aponta que a probabilidade de acontecerem erros no lançamento das informações é alta, não só por limitações dos técnicos das escolas (que usualmente são responsáveis por essa anotação), mas também por problemas relativos ao questionário do Censo e às possibilidades de registro. A autora constata que a escola relaciona diversas condições (dificuldade de aprendizagem, diabetes, problemas psiquiátricos) como deficiência, o que não só altera o resultado do Censo como também rotula o aluno como sendo da Educação Especial.

No tocante às instruções para preenchimento do Censo Escolar, ao verificar os Cadernos de Instruções (BRASIL, 2008b, 2009a, 2010b, 2011c, 2012a, 2013a) - documentos que servem de guia para preenchimento do sistema Educacenso -, Leijoto (2015) alerta que algumas categorias de deficiências estão listadas na identificação em alguns anos e em outros "desaparecem", o que induz a erros nos relatórios dos casos. Esses aspectos indicam a imprecisão do significado do número de matrículas visto na Tabela 1.

O gráfico a seguir exibe o total de matrículas de alunos da Educação Especial no ensino comum no Brasil segundo a região, a partir da publicação do Programa de Implantação de Salas de Recursos Multifuncionais e do incentivo de recursos proporcionado pelo Fundeb, no ano de 2007: 
GRÁFICO 1 - Número de matrículas de alunos da Educação Especial em classes comuns, segundo a região do Brasil, 2007 a 2014

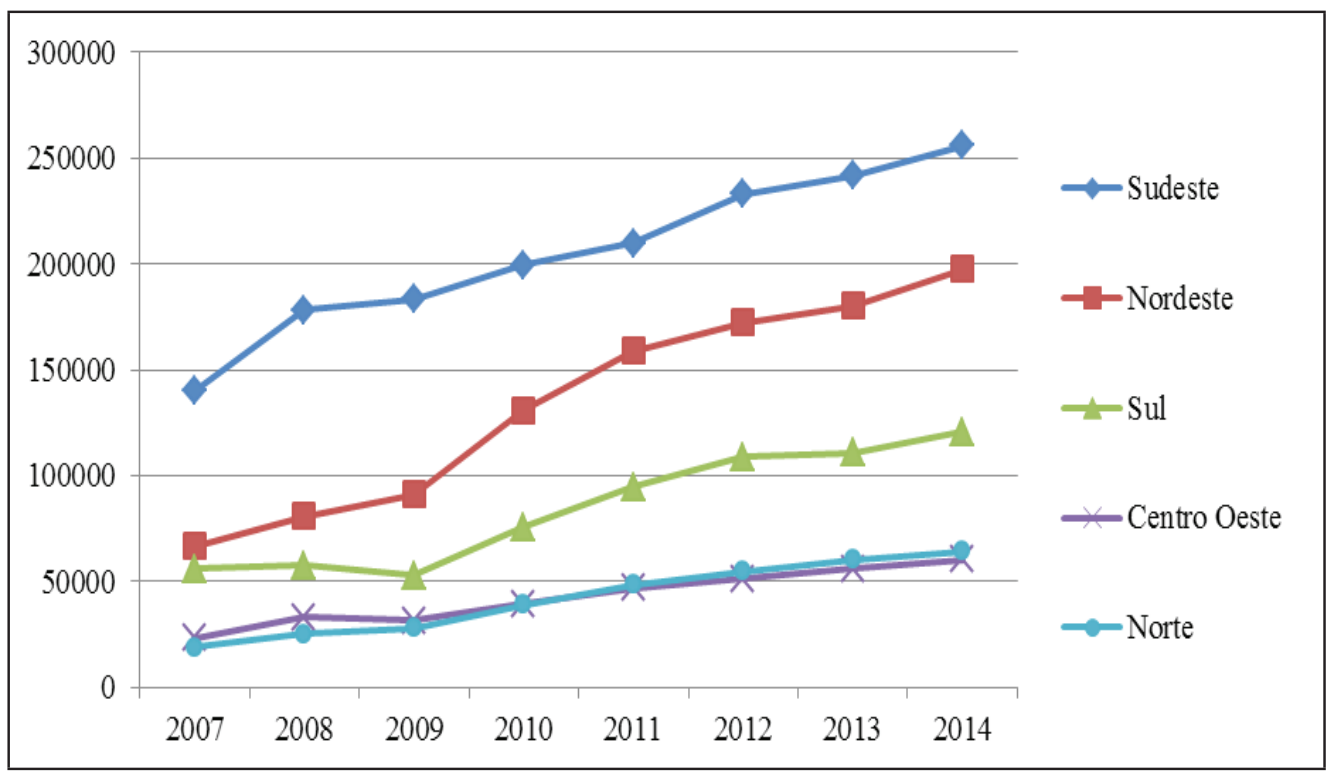

Fonte: MEC/Inep/Censo Escolar/Sinopse Estatística da Educação Básica. Brasil, 2007 a 2014 (elaboração própria).

O número de matrículas de alunos da Educação Especial aumentou em todas as regiões no período de 2007 a 2014. Considerando o foco da política educacional de universalização da educação no país, esse aumento é promissor, todavia insuficiente para conhecer as condições da escolarização desses alunos no sistema escolar como permanência, participação e desempenho (LAPLANE, 2015). Diferentemente de sucesso, trabalhos acadêmicos têm evidenciado limitações do funcionamento da escola quanto ao desenvolvimento acadêmico dessa população, com a identificação dos seguintes problemas: concentração de matrículas nas primeiras séries do ensino fundamental (MELETTI; RIBEIRO, 2014), pouco acesso ao conhecimento sistematizado (CARVALHO, 2013; PLETSCH, 2013) e pouco acesso ao atendimento educacional especializado (REBELO, 2012).

Os dados da Tabela 1 podem ser visualizados em contraste com as informações prestadas pelo documento Plano Nacional de Educação PNE 2014-2024: Linha de Base (BRASIL, 2015), elaborado pela Diretoria de Estudos Educacionais para 
2 Disponível em: $<$ http://tabnet datasus.gov.br/>. Acesso em: 30 jul. 2016 acompanhamento das metas e estratégias do Plano Nacional de Educação. O documento informa que, segundo o Censo Demográfico de 2010, de um total de 1.819 .712 crianças e adolescentes de 4 a 17 anos que não conseguiam de modo algum ou tinham grande dificuldade para enxergar, ouvir, caminhar ou subir degraus, ou ainda possuíam alguma deficiência mental/intelectual permanente que limitava suas atividades habituais, $1.560 .784(85,8 \%)$ frequentavam escolas ou creches e $14,2 \%$ encontravam-se fora da escola. Se o documento consigna o número de 1.560 .784 desses alunos na escola, o que explicaria apenas 886.815 matrículas no Censo Escolar de 2014 (BRASIL, 2007c, 2008c, 2009b, 2010c, 2011d, 2012b, 2013b, 2014c)?

No que tange à incidência de deficiência no país, há ainda a Pesquisa Nacional de Saúde (IBGE) de 2013, que assevera que a proporção de brasileiros com alguma deficiência é de 6,2\%, enquanto o Censo Demográfico de 2010 traz um percentual de 23,9\%. Diante de bases de dados com fontes e instrumentos de coletas diferentes que levam a resultados também diferentes, somente é possível constatar, quanto às matrículas de alunos da Educação Especial na educação básica, um aumento do número em classes comuns e uma diminuição em classes especiais e escolas exclusivas, mas não existe clareza quanto ao alcance da sua escolarização.

Apesar da implantação da política de educação inclusiva, ainda há formas de atendimento segregado, característica anteriormente constatada por alguns autores (PRIETO, 2010; KASSAR; MELETTI, 2012). A literatura (JANNUZZI, 1985; BUENO, 1991) mostra que a maior parte das escolas especializadas se encontra sob a administração privada (principalmente filantrópica). Para compreender a participação desse setor a partir do momento de inflexão das matrículas, separamos os dados em classes comuns, especiais e escolas exclusivas, conforme dependência administrativa, no período de 2007 a 2014, nas próximas três tabelas: 
TABELA 2 - Distribuição do número de matrículas de alunos da Educação Especial em classes comuns, por dependência administrativa. Brasil, 2007 a 2014

\begin{tabular}{c|c|c|c|c|c}
\hline \multirow{2}{*}{ ANO } & \multirow{2}{*}{ TOTAL } & \multicolumn{2}{|c|}{ PÚBLICA } & \multicolumn{2}{c}{ PRIVADA } \\
\cline { 3 - 6 } & & $\mathbf{N}$ & $\%$ & $\mathbf{N}$ & $\%$ \\
\hline 2007 & 306.136 & 285.923 & 93,4 & 20.213 & 6,6 \\
\hline 2008 & 375.775 & 352.638 & 93,8 & 23.137 & 6,2 \\
\hline 2009 & 387.031 & 365.796 & 94,5 & 21.235 & 5,5 \\
\hline 2010 & 484.332 & 457.236 & 94,4 & 27.096 & 5,6 \\
\hline 2011 & 558.423 & 525.812 & 94,2 & 32.611 & 5,8 \\
\hline 2012 & 620.777 & 583.619 & 94,0 & 37.158 & 6,0 \\
\hline 2013 & 648.921 & 609.839 & 94,0 & 39.082 & 6,0 \\
\hline 2014 & 698.768 & 655.375 & 93,8 & 43.393 & 6,2 \\
\hline
\end{tabular}

Fonte: MEC/Inep/Censo Escolar da Educação Básica (elaboração própria).

TABELA 3 - Distribuição do número de matrículas de alunos da Educação Especial em classes especiais, por dependência administrativa. Brasil, 2007 a 2014

\begin{tabular}{c|c|c|c|c|c}
\hline \multirow{2}{*}{ ANO } & \multirow{2}{*}{ TOTAL } & \multicolumn{2}{|c|}{ PÚBLICA } & \multicolumn{2}{c}{ PRIVADA } \\
\cline { 3 - 6 } & & N & $\%$ & N & $\%$ \\
\hline 2007 & 76.765 & - & - & - & - \\
\hline 2008 & 73.969 & - & - & - & - \\
\hline 2009 & 53.430 & 50.269 & 94,0 & 3.161 & 6,0 \\
\hline 2010 & 46.255 & 42.208 & 91,2 & 4.047 & 8,8 \\
\hline 2011 & 37.497 & 33.684 & 89,8 & 3.813 & 10,2 \\
\hline 2012 & 31.168 & 28.025 & 89,9 & 3.143 & 10,1 \\
\hline 2013 & 30.453 & 26.538 & 87,1 & 3.915 & 12,9 \\
\hline 2014 & 27.004 & 24.009 & 88,9 & 2.995 & 11,1 \\
\hline
\end{tabular}

Fonte: MEC/Inep/Censo Escolar da Educação Básica. Matrículas em classes especiais do ensino regular e/ou da educação de jovens e adultos. Os dados de 2007 e 2008 não estavam disponíveis por completo nas fontes consultadas (elaboração própria). 
TABELA 4 - Matrículas de alunos com deficiência nas escolas exclusivamente especiais, por dependência administrativa. Brasil, 2007 a 2014

\begin{tabular}{c|c|c|c|c|c}
\hline \multirow{2}{*}{ ANO } & \multirow{2}{*}{ TOTAL } & \multicolumn{2}{|c|}{ PÚBLICA } & \multicolumn{2}{c}{ PRIVADA } \\
\cline { 3 - 6 } & & $\mathbf{N}$ & $\%$ & $\mathbf{N}$ & $\%$ \\
\hline 2007 & 270.742 & 57.216 & 21,1 & 213.526 & 78,9 \\
\hline 2008 & 245.443 & 50.448 & 20,6 & 194.995 & 79,4 \\
\hline 2009 & 199.257 & 38.862 & 19,5 & 160.395 & 80,5 \\
\hline 2010 & 172.016 & 33.176 & 19,3 & 138.840 & 80,7 \\
\hline 2011 & 156.385 & 29.400 & 18,8 & 126.985 & 81,2 \\
\hline 2012 & 168.488 & 30.200 & 17,9 & 138.288 & 82,1 \\
\hline 2013 & 163.968 & 28.089 & 17,1 & 135.879 & 82,9 \\
\hline 2014 & 161.043 & 27.736 & 17,2 & 133.307 & 82,8 \\
\hline
\end{tabular}

Fonte: MEC/Inep/Censo Escolar da Educação Básica (elaboração própria).

No período, mais de $90 \%$ das matrículas em classes comuns pertenciam ao setor público (Tabela 2). Nas classes especiais, o setor público também concentrava o maior número de matrículas. As classes especiais tiveram diminuição de matrículas ao longo dos anos, tanto no setor público quanto no privado (Tabela 3). As matrículas em escolas exclusivamente especiais confirmam as informações da literatura, que ressalta a força do setor privado nessa forma de atendimento (Tabela 4).

Para compreender os números da Educação Especial em termos da política educacional atual, cabe verificar a existência do atendimento educacional especializado.

\section{MATRÍCULAS EM ATENDIMENTO EDUCACIONAL ESPECIALIZADO NO BRASIL}

O Programa Implantação de Salas de Recursos Multifuncionais, conduzido pelo MEC/Secretaria de Educação Continuada, Alfabetização, Diversidade e Inclusão, estabelecido por meio da Portaria Ministerial n. 13/2007 (BRASIL, 2007a), passou a integrar o Plano de Desenvolvimento da Educação (PDE) e o Plano Nacional dos Direitos da Pessoa com Deficiência - Viver sem Limite. O programa instituiu a forma e o lócus atuais (a política atual) do atendimento educacional especializado em implantação no país. No contexto da Política Nacional de Educação Especial na Perspectiva da 
Educação Inclusiva, o programa objetiva: apoiar a organização da Educação Especial na perspectiva da educação inclusiva; assegurar o pleno acesso dos estudantes público-alvo da Educação Especial no ensino regular em igualdade de condições com os demais estudantes; disponibilizar recursos pedagógicos e de acessibilidade às escolas regulares da rede pública de ensino; e promover o desenvolvimento profissional e a participação da comunidade escolar (BRASIL, 2012c).

Aos gestores dos sistemas de ensino compete a definição da implantação das salas de recursos multifuncionais, o planejamento da oferta do Atendimento Educacional Especializado (AEE) e a indicação das escolas a serem inseridas, de acordo com as demandas da rede. Destaca-se que há a opção clara da escola pública como lócus do programa: “a escola indicada deve ser da rede pública de ensino regular, conforme o Censo Escolar MEC/Inep (escola comum)" (BRASIL, 2012c, p. 10, grifo nosso), mesmo com a aprovação do Decreto n. 7.611/2011 (BRASIL, 2011b), que garantiu o AEE em instituições privado-assistenciais de caráter filantrópico.

Até o ano de 2014, segundo a versão preliminar do Relatório Educação para Todos 2000-2015, foram implantadas 42 mil salas de recursos multifuncionais com equipamentos, mobiliários, materiais pedagógicos e recursos de acessibilidade, para o atendimento educacional especializado, em $49 \%$ das escolas públicas de ensino regular com matrícula de estudantes da Educação Especial, localizadas em 93\% dos municípios brasileiros. Segundo o Ministério da Educação, foram ofertados cursos de formação continuada para professores que atuam no atendimento educacional especializado dessas escolas, apoio financeiro para a acessibilidade arquitetônica nos prédios escolares e a aquisição de tecnologia assistiva (BRASIL, 2014b). Apresenta-se, a seguir, a comparação entre o número de matrículas em Atendimento Educacional Especializado no país e o número de matrículas no ensino regular de alunos da Educação Especial e a cobertura do programa. Como informado, os dados foram disponibilizados apenas a partir de 2009. 
TABELA 5 - Atendimento educacional especializado complementar (AEE). Brasil, 2009 a 2014

\begin{tabular}{|c|c|c|c|c|c|}
\hline \multirow[b]{2}{*}{ ANO } & \multicolumn{3}{|c|}{ NÚMERO DE MATRÍCULAS } & \multirow{2}{*}{$\begin{array}{c}\% \\
(B: A)\end{array}$} & \multirow{2}{*}{$\begin{array}{c}\% \\
(C: B)\end{array}$} \\
\hline & $\begin{array}{l}\text { EDUCAÇÃO BÁSICA - } \\
\text { TOTAL GERAL [A] }\end{array}$ & $\begin{array}{l}\text { EDUCAÇÃO ESPECIAL } \\
\text { EM CLASSES COMUNS - } \\
\text { ALUNOS INCLUÍDOS [B] }\end{array}$ & $\begin{array}{c}\text { ATENDIMENTO } \\
\text { EDUC. ESPEC. } \\
\text { COMPLEMENTAR (AEE) [C] }\end{array}$ & & \\
\hline 2009 & 52.580 .452 & 387.031 & 129.697 & 0,74 & 33,5 \\
\hline 2010 & 51.549 .889 & 484.332 & 176.706 & 0,94 & 36,5 \\
\hline 2011 & 50.972 .619 & 558.423 & 231.740 & 1,09 & 41,5 \\
\hline 2012 & 50.545 .050 & 620.777 & 248.878 & 1,22 & 40,1 \\
\hline 2013 & 50.042 .448 & 648.921 & 290.799 & 1,29 & 44,8 \\
\hline 2014 & 49.771 .371 & 698.768 & 306.746 & 1,40 & 43,9 \\
\hline $\begin{array}{l}\text { Variação } \\
\text { (\%) }\end{array}$ & (-) 5,34 & 80,5 & 136,5 & 0,75 & 10,4 \\
\hline
\end{tabular}

Fonte: MEC/Inep/Censo Escolar da Educação Básica. Brasil, 2009 a 2014 (elaboração própria).

Vale lembrar que a Tabela 1, no início deste artigo, em sua última coluna, compara as matrículas da Educação Especial em todos os serviços e modalidades (escolas especializadas, classes especiais e classes comuns/ensino regular) em relação ao total de matrículas em geral. Já nessa Tabela 5, a quinta coluna exibe a comparação das matrículas de alunos da Educação Especial no ensino regular (classes comuns apenas) em relação ao total de matrículas na educação básica. Por esse motivo, as porcentagens nas duas tabelas são diferentes.

Na Tabela 5, constata-se que no período de 2009 a 2014 o número total de matrículas na educação básica diminuiu $5,34 \%$, enquanto o número total de matrículas de alunos da Educação Especial nas classes comuns aumentou 80,5\%. O número total de matrículas em AEE sofreu um aumento de $136,5 \%$, mas a cobertura do programa aumentou apenas 10,4\%. Apesar do grande número de estabelecimentos com salas de recursos que oferecem AEE, o alcance do programa não chegou a atender 50\% dos alunos público-alvo da política, matriculados no ensino comum, o que sugere que grande parcela desses alunos pode não estar recebendo atendimento educacional especializado. A análise desses dados indica que a proposta, a princípio hegemônica, não chega a conquistar essa premência na execução da política na escola. 


\section{CONSIDERAÇÕES FINAIS}

No início do texto, enfatizou-se a reserva da área da educação em relação a pesquisas que tratam de dados quantitativos e buscou-se analisar a utilização de indicadores educacionais para o conhecimento da realidade educacional. O foco versou sobre as matrículas de alunos na Educação Especial no Brasil entre 1974 e 2014, com a intenção de que fossem compreendidas, considerando aspectos da política educacional no período. Enfatizaram-se questões referentes à política atual, que preconiza a matrícula de todos os alunos na educação comum e o oferecimento de atendimento educacional especializado no contraturno, quando necessário.

Apesar das limitações evidenciadas na literatura (JANNUZZI, 2009; SASS, 2012; MELETTI; BUENO, 2010, 2013), algumas das quais citadas neste texto, os dados oficiais são utilizados pelos governos para propor e justificar ações públicas, sob uma perspectiva pragmática, que tem se sobreposto a uma avaliação crítica, afetando as condições de vida de grande parte da população (POPKEWITZ; LINDBLAD, 2001).

$\mathrm{O}$ aumento das matrículas nas classes comuns tem sido celebrado pelo Ministério da Educação como indicador do sucesso da política de inclusão escolar,

[...] mostrando a efetivação da educação inclusiva e o empenho das redes de ensino em envidar esforços para organizar uma política pública universal e acessível às pessoas com deficiência. (BRASIL, 2014a, p. 25)

A afirmação de sucesso da política de educação inclusiva remete à adoção, pelo Governo Federal, de um diagnóstico de certa forma superficial e parcial dos dados existentes. Pelo modo como os dados aparecem nos relatórios oficiais, não se verifica, por exemplo, que, em 40 anos, a despeito da implantação da política de educação inclusiva e do aumento do número de matrículas de alunos da Educação Especial, a sua proporção em relação ao total de matrículas na educação básica não chega a $2 \%$ (pois, em 40 anos, também cresceu a taxa de matrícula geral da população). Considerando que o número de matrículas não designa necessariamente o número de alunos nas escolas, devido às duplas matrículas, de 
fato não se sabe ao certo qual foi o avanço da escolarização da população-alvo da Educação Especial no período.

Para a investigação sobre a situação de escolaridade dessa população, devem ser apreciados, ainda, estudos como os nomeados neste texto, que questionam a utilização apenas de indicadores de matrícula como demonstrativos dos avanços da política, sem incluir outros indicadores e diferentes informações que favoreçam a averiguação dos processos de permanência desses alunos na escola, bem como informações sobre as condições materiais e objetivas em que vem ocorrendo a sua escolarização. Diferentes pesquisas no campo da educação (EMER, 2011; MICHELS; GARCIA, 2010) mostram que a matrícula desses alunos na escola não garante, necessariamente, a realização do atendimento adequado (JORDÃO, 2013; MELO, 2008) e que o atendimento educacional especializado nas salas de recursos multifuncionais (que constitui o âmago da política atual de atendimento educacional especializado) também não tem respondido a todas as características e necessidades acadêmicas dos alunos (ALBUQUERQUE, 2008; ARARUNA, 2013; ARNAL, 2007).

Os dados estatísticos propiciam diferentes leituras. Se, por um lado, o término de um programa, a sua descontinuidade ou o fechamento de um órgão significam qualidades para a gestão pública gerencial, por outro, afetam as condições de vida de grande parcela da população, que depende exclusivamente das políticas públicas. Aqui é preciso relembrar o desafio expresso por Freitas (2013) sobre o papel de análise independente dos pesquisadores em relação ao material que circula como verdade. A academia, em posse de indicadores sociais e de um conjunto bastante relevante de pesquisas nas mais diferentes áreas (em política educacional, sobre o cotidiano de sala de aula, em didática colaborativa, entre outras), muitas das quais expostas neste artigo, pode compreender tais números com um olhar que transcenda uma perspectiva parcial/superficial, avaliando-os no contexto histórico e político em que são construídos. 


\section{REFERÊNCIAS}

ALBUQUERQUE, Rosana Aparecida. Educação e inclusão escolar: a prática pedagógica na sala de recursos de $5^{\mathrm{a}}$ a $8^{\mathrm{a}}$ séries. 2008. $144 \mathrm{f}$. Dissertação (Mestrado em Educação) - Universidade Estadual de Maringá, Maringá, 2008.

ALMEIDA, Ivan Castro de; WOLYNEC, Elisa. A produção de indicadores educacionais no Brasil e a comparação internacional. Revista Brasileira de Estudos Pedagógicos, Brasília, DF, v. 79, n. 193, p. 148-160, set./dez. 1998.

ANACHE, Alexandra Ayach. Diagnóstico ou inquisição: estudo sobre o uso do diagnóstico psicológico na escola. 1997. Tese (Doutorado em Psicologia) Universidade de São Paulo, São Paulo, 1997.

ARARUNA, Maria Rejane. Dos desafios às possibilidades: a prática pedagógica do professor do atendimento educacional especializado com o aluno que apresenta deficiência intelectual. 2013. 281 f. Dissertação (Mestrado em Educação Brasileira) - Universidade Federal do Ceará, Fortaleza, 2013.

ARNAL, Leila de Souza Peres. Educação escolar inclusiva: a prática pedagógica nas salas de recursos. 2007. 133 f. Dissertação (Mestrado em Educação) Universidade Estadual de Maringá, Maringá, 2007.

BONAMINO, Alicia Maria Catalano; OLIVEIRA, Lúcia Helena Gazólis de. Estudos longitudinais e pesquisa na educação básica. Linhas Críticas, Brasília, DF, v. 19, n. 38, p. 33-50, jan./abr. 2013.

BRASIL. Decreto n. 42.728, de 3 de dezembro de 1957. Institui a Campanha para a Educação do Surdo Brasileiro. Brasília, DF: Presidência da República, 1957.

BRASIL. Decreto n. 44.236, de 1 de agosto de 1958. Institui a Campanha Nacional de Educação e Reabilitação dos Deficitários Visuais. Brasília, DF: Presidência da República, 1958.

BRASIL. Decreto n. 48.961, de 22 de setembro de 1960. Institui a Campanha Nacional de Educação e Reabilitação de Deficientes Mentais. Brasília, DF: Presidência da República, 1960.

BRASIL. Lei n. 5.692, de 11 de agosto de 1971. Fixa diretrizes e bases para o ensino de $1^{\circ}$ e $2^{\circ}$ graus, e dá outras providências. Diário Oficial [da] República Federativa do Brasil, Brasília, DF, 1971.

BRASIL. Ministério da Educação e Cultura. Portaria n. 215, de 20 de agosto de 1973. Brasília, DF: MEC, 1973a.

BRASIL. Ministério da Educação e Cultura. Portaria n. 233, de 4 de setembro de 1973. Brasília, DF: MEC, 1973b.

BRASIL. Presidência da República. Decreto n. 72.425, de 3 de jultho de 1973. Cria o Centro Nacional de Educação Especial (Cenesp), e dá outras providências. Brasília, DF, 1973c.

BRASIL. Ministério da Educação e Cultura. Centro Nacional de Educação Especial. Serviço de Estatística da Educação e Cultura. Educação Especial: dados estatísticos - 1974. Brasília, DF: SEEC/DDD, 1975. v. 1. 
BRASIL. Ministério da Educação e Cultura. Serviço de Estatística da Educação e Cultura. Centro Nacional de Educação Especial. Educação Especial no Brasil: síntese estatística. Brasília, DF: SEEC, 1984.

BRASIL. Ministério da Educação. Serviço de Estatística da Educação e Cultura. Centro Nacional de Educação Especial. Sinopse estatística da educação especial 1981. Brasília, DF: SEEC, 1985. v. 3.

BRASIL. Decreto n. 93.613, de 21 de novembro de 1986. Extingue órgãos do Ministério da Educação, e dá outras providências. Brasília, DF: Presidência da República, 1986.

BRASIL. Constituição da República Federativa do Brasil (1988). Brasília, DF: Senado Federal, 1988.

BRASIL. Ministério da Educação. Coordenação de Informações e Planejamento. Sinopse Estatística da Educação Especial 1988: ensino regular. Brasília, DF: MEC/CIP, 1991a. v. 1.

BRASIL. Ministério da Educação. Coordenação de Informações e Planejamento. Sinopse Estatística da Educação Especial 1988: instituições especializadas. Brasília, DF: MEC/CIP, 1991b. v. 2.

BRASIL. Presidência da República. Câmara da Reforma do Estado. Plano Diretor da Reforma do Aparelho do Estado. Brasília, DF, 1995.

BRASIL. Ministério da Educação. Lei n. 9.394, de 20 de dezembro de 1996. Estabelece as diretrizes e bases da educação nacional. Brasília, DF, 1996.

BRASIL. Instituto Nacional de Estudos e Pesquisas Educacionais Anísio Teixeira. Sinopse estatística, 1996: Brasil, regiões e unidades da Federação. Brasília, DF: Inep, 1997.

BRASIL. Ministério da Educação. Instituto Nacional de Estudos e Pesquisas Educacionais Anísio Teixeira. Sinopse estatística da educação especial MEC/Inep - 1998. Brasília, DF: MEC/Inep, 1998a.

BRASIL. Ministério da Educação. Instituto Nacional de Estudos e Pesquisas Educacionais Anísio Teixeira. Informe estatístico da educação básica: evolução recente das estatísticas da educação básica no Brasil - 1998. Brasília, DF: Inep, 1998b.

BRASIL. Ministério da Educação. Instituto Nacional de Estudos e Pesquisas Educacionais Anísio Teixeira. Sinopse estatística da educação básica MEC/Inep - 1998. Brasília, DF: MEC/Inep, 1998c.

BRASIL. Ministério da Educação. Instituto Nacional de Estudos e Pesquisas Educacionais Anísio Teixeira. Sinopse estatística da educação básica MEC/Inep - 2000. Brasília, DF: MEC/Inep, 2000.

BRASIL. Conselho Nacional de Educação. Câmara de Educação Básica. Resolução n. 2, de 11 de setembro de 2001. Diretrizes nacionais para educação especial na educação básica. Brasília, DF, 2001.

BRASIL. Ministério da Educação. Instituto Nacional de Estudos e Pesquisas Educacionais Anísio Teixeira. Sinopse estatística da educação básica MEC/Inep - 2002. Brasília, DF: MEC/Inep, 2002. 
BRASIL. Ministério da Educação. Portaria Normativa n. 13, de 24 de abril de 2007. Dispõe sobre a criação do "Programa de Implantação de Salas de Recursos Multifuncionais”. Brasília, DF, 2007a.

BRASIL. Presidência da República. Lei n. 11.494/2007, de 20 de junho de 2007. Regulamenta o Fundo de Manutenção e Desenvolvimento da Educação Básica e de Valorização dos Profissionais da Educação - Fundeb - e dá outras providências. Brasília, DF, 2007b.

BRASIL. Ministério da Educação. Instituto Nacional de Estudos e Pesquisas Educacionais Anísio Teixeira. Microdados do censo escolar da educação básica 2007. Brasília, DF: MEC/Inep, 2007c.

BRASIL. Ministério da Educação. Secretaria de Educação Especial. Política Nacional de Educação Especial na Perspectiva da Educação Inclusiva. Brasília, DF: SEESP, 2008a.

BRASIL. Ministério da Educação. Instituto Nacional de Estudos e Pesquisas Educacionais Anísio Teixeira. Censo escolar da educação básica 2008: cadernos de instruções. Brasília, DF: DEED/CGCE, 2008b.

BRASIL. Ministério da Educação. Instituto Nacional de Estudos e Pesquisas Educacionais Anísio Teixeira. Microdados do censo escolar da educação básica 2008. Brasília, DF: MEC/Inep, 2008c.

BRASIL. Ministério da Educação. Instituto Nacional de Estudos e Pesquisas Educacionais Anísio Teixeira. Censo escolar da educação básica 2009: cadernos de instruções. Brasília, DF: DEED/CGCE, 2009a.

BRASIL. Ministério da Educação. Instituto Nacional de Estudos e Pesquisas Educacionais Anísio Teixeira. Microdados do censo escolar da educação básica 2009. Brasília, DF: MEC/Inep, 2009b.

BRASIL. Ministério da Educação. Instituto Nacional de Estudos e Pesquisas Educacionais Anísio Teixeira. Sinopse estatística da educação especial MEC/Inep - 2010. Brasília, DF: MEC/Inep, 2010a.

BRASIL. Ministério da Educação. Instituto Nacional de Estudos e Pesquisas Educacionais Anísio Teixeira. Censo escolar da educação básica 2010: cadernos de instruções. Brasília, DF: DEED/CGCE, 2010b.

BRASIL. Ministério da Educação. Instituto Nacional de Estudos e Pesquisas Educacionais Anísio Teixeira. Microdados do censo escolar da educação básica 2010. Brasília, DF: MEC/Inep, 2010c.

BRASIL. Presidência da República. Decreto n. 7.480, de 16 de maio de 2011. Aprova a Estrutura Regimental e o Quadro Demonstrativo dos Cargos em Comissão do Grupo Direção e Assessoramento Superiores - DAS e das Funções Gratificadas do Ministério da Educação e dispõe sobre remanejamento de cargos em comissão. Brasília, DF, 2011a.

BRASIL. Presidência da República. Decreto n. 7.611, de 17 de novembro de 2011. Dispõe sobre a educação especial, o atendimento educacional especializado, e dá outras providências. Brasília, DF, 2011b. 
BRASIL. Ministério da Educação. Instituto Nacional de Estudos e Pesquisas Educacionais Anísio Teixeira. Censo escolar da educação básica 2011: cadernos de instruções. Brasília, DF: DEED/CGCE, 2011c.

BRASIL. Ministério da Educação. Instituto Nacional de Estudos e Pesquisas Educacionais Anísio Teixeira. Microdados do censo escolar da educação básica 2011. Brasília, DF: MEC/Inep, 2011d.

BRASIL. Ministério da Educação. Instituto Nacional de Estudos e Pesquisas Educacionais Anísio Teixeira. Censo escolar da educação básica 2012: cadernos de instruções. Brasília, DF: DEED/CGCE, 2012a.

BRASIL. Ministério da Educação. Instituto Nacional de Estudos e Pesquisas Educacionais Anísio Teixeira. Microdados do censo escolar da educação básica 2012. Brasília, DF: MEC/Inep, 2012b.

BRASIL. Ministério da Educação. Secretaria de Educação Continuada, Alfabetização, Diversidade e Inclusão. Documento orientador do Programa Implantação de Salas de Recursos Multifuncionais. Brasília, DF: Secadi, 2012c.

BRASIL. Ministério da Educação. Instituto Nacional de Estudos e Pesquisas Educacionais Anísio Teixeira. Censo escolar da educação básica 2013: caderno de instruções. Brasília, DF: DEED/CGCE, 2013a.

BRASIL. Ministério da Educação. Instituto Nacional de Estudos e Pesquisas Educacionais Anísio Teixeira. Microdados do censo escolar da educação básica 2013. Brasília, DF: MEC/Inep, 2013b.

BRASIL. Instituto Nacional de Estudos e Pesquisas Educacionais Anísio Teixeira. Censo escolar da educação básica 2013: resumo técnico. Brasília, DF: Inep, 2014a.

BRASIL. Ministério da Educação. Relatório Educação para Todos 2000-2015: versão preliminar. jun. 2014. Brasília, DF: MEC, 2014b.

BRASIL. Ministério da Educação. Instituto Nacional de Estudos e Pesquisas Educacionais Anísio Teixeira. Microdados do censo escolar da educação básica 2014. Brasília, DF: MEC/Inep, 2014c.

BRASIL. Instituto Nacional de Estudos e Pesquisas Educacionais Anísio Teixeira. Plano Nacional de Educação PNE 2014-2024: linha de base. Brasília, DF: Inep, 2015.

BROOKE, Nigel. Controvérsias sobre políticas de alto impacto. Cadernos de Pesquisa, São Paulo, v. 43, n. 148, p. 336-347, jan./abr. 2013.

BUENO, José Geraldo Silveira. Educação especial brasileira: a integração/ segregação do aluno diferente. 1991. 214 f. Tese (Doutorado em Educação) Pontifícia Universidade Católica de São Paulo, São Paulo, 1991.

CARVALHO, Maria de Fátima. O aluno com deficiência intelectual na escola: ensino, aprendizagem e desenvolvimento humano. In: MELETTI, Silvia Márcia Ferreira; KASSAR, Mônica de Carvalho Magalhães (Org.). Escolarização de alunos com deficiências: desafios e possibilidades. Campinas, SP: Mercado de Letras, 2013. p. 203-241. 
DIAS, Patrícia Jovino de Oliveira. 0 registro de dados sobre alunos com necessidades educacionais especiais no censo escolar da educação básica na rede municipal de ensino de Londrina/PR. 2014. 134 f. Dissertação (Mestrado em Educação) - Universidade Estadual de Londrina, Londrina, 2014.

DINIZ, Ednar Maria Vieira. O censo escolar. Revista Brasileira de Estudos Pedagógicos, Brasília, DF, v. 80, n. 194, p. 156-163, jan./abr. 1999.

EMER, Simone de Oliveira. Inclusão escolar: formação docente para o uso das TICs aplicada como tecnologia assistiva na sala de recurso multifuncional e a sala de aula. 2011. 163 f. Dissertação (Mestrado em Educação) - Universidade Federal do Rio Grande do Sul, Porto Alegre, 2011.

FERRARO, Alceu Ravanello. Utilização das estatísticas educacionais dos censos demográficos e dos registros escolares: uma tipologia de análises. Educação e Realidade, Porto Alegre, v. 4, n. 2, p. 253-266, 1979.

FERRARO, Alceu Ravanello. Quantidade e qualidade na pesquisa em educação, na perspectiva da dialética marxista. Pro-Posições, Campinas, v. 23, n. 1, p. 129-146, jan./abr. 2012.

FERREIRA, Júlio Romero. A exclusão da diferença. Piracicaba, SP: Ed. Unimep, 1993.

FRANCO, Maria Laura P. Barbosa. Pesquisa educacional: algumas reflexões. Cadernos de Pesquisa, São Paulo, n. 51, p. 84-87, nov. 1984.

FRANCO, Maria Laura P. Barbosa; GOLDBERG, Maria Amélia Azevedo. Prioridades em pesquisa educacional: prós e contras. Cadernos de Pesquisa, São Paulo, n. 16, p. 74-80, nov. 1976.

FREITAS, Luiz Carlos de. Políticas de responsabilização: entre a falta de evidência e a ética. Cadernos de Pesquisa, São Paulo, v. 43, n. 148, p. 348-365, jan./abr. 2013.

GAMBOA, Silvio Ancízar Sanchez. A dialética na pesquisa em educação: elementos de contexto. In: FAZENDA, Ivani (Org.). Metodologia da pesquisa educacional. 3. ed. São Paulo: Cortez, 1994. p. 91-115.

GATTI, Bernardete Angelina (Org.). Alternativas metodológicas para a pesquisa educacional: conhecimento e realidade. Cadernos de Pesquisa, São Paulo, v. 40, p. 4-6, fev. 1982.

GATTI, Bernardete Angelina. A construção da pesquisa em educação no Brasil. Brasília, DF: Plano, 2002.

GOERGEN, Pedro. A pesquisa educacional no Brasil: dificuldades, avanços e perspectivas. Em Aberto, Brasília, DF, ano 5, n. 31, p. 1-17, jul./set. 1985.

GOUVEIA, Aparecida Joly. A pesquisa educacional no Brasil: de 1970 para cá. Cadernos de Pesquisa, São Paulo, n. 19, p. 75-79, dez. 1976.

INSTITUTO BRASILEIRO DE GEOGRAFIA E ESTATÍSTICA. Censo Demográfico de 2010. Rio de Janeiro: IBGE, 2010. Disponível em: <https://www.ibge.gov.br/>. Acesso em: 07 jun. 2017. 
INTERNATIONAL BUSINESS MACHINES. Software IBM (International Business Machines) SPSS Statistics. Versão 17.

JANNUZZI, Gilberta Sampaio de Martino. A luta pela educação do deficiente mental no Brasil. São Paulo: Cortez; Autores Associados, 1985.

JANNUZZI, Paulo de Martino. Indicadores para diagnóstico, monitoramento e avaliação de programas sociais no Brasil. Revista do Serviço Público, Brasília, DF, v. 56, n. 2, p. 137-159, 2005.

JANNUZZI, Paulo de Martino. Indicadores sociais no Brasil: conceitos, fontes de dados e aplicações. 4. ed. Campinas, SP: Alínea, 2009.

JANNUZZI, Paulo de Martino. Avaliação de programas sociais: conceitos e referências de quem a realiza. Estudos em Avaliação Educacional, São Paulo, v. 25, n. 58, p. 22-42, maio/ago. 2014a.

JANNUZZI, Paulo de Martino. A produção de informação e conhecimento para aprimoramento das políticas e programas de desenvolvimento social: princípios, conceitos e caracterização das pesquisas de avaliação realizadas pela SAGI/MDS de 2011 a 2014. In: JANNUZZI, Paulo de Martino; QUIROGA, Júnia (Org.). Síntese das pesquisas de avaliação de programas sociais do MDS 2011-2014. Brasília, DF: Ministério do Desenvolvimento Social e Combate à Fome, SAGI, 2014b. p. 12-35. (Cadernos de Estudos: Desenvolvimento Social em Debate, n. 16).

JANNUZZI, Paulo de Martino et al. Estruturação de sistemas de monitoramento e especificação de pesquisas de avaliação: os problemas dos programas públicos são. In: ESCOLA NACIONAL DE ADMINISTRAÇÃO PÚBLICA (Org.). Reflexões para a Ibero-América: avaliação de programas sociais. 1. ed. Brasília, DF: Enap, 2009. p. 101-138. (Caderno EIAPP).

JORDÃO, Suelen Garay Figueiredo. Política de inclusão escolar na ótica de professores das salas de recursos multifuncionais. 2013. 132 f. Dissertação (Mestrado em Educação) - Universidade do Vale do Itajaí, Itajaí, 2013.

KASSAR, Mônica de Carvalho Magalhães. Diagnosticar a deficiência: sim ou não? Revista Brasileira de Educação Especial, Marília, v. 1, n. 2, p. 85-92, 1994.

KASSAR, Mônica de Carvalho Magalhães; MELETTI, Silvia Márcia Ferreira. Análise de possíveis impactos do Programa Educação Inclusiva: direito à diversidade. Ciências Humanas e Sociais em Revista, Rio de Janeiro, v. 34, n. 12, p. 49-63, jan./jun. 2012.

LAPLANE, Adriana Lia Friszman de. O que os dados do censo escolar revelam sobre as barreiras à inclusão escolar? Educação e Fronteiras, Dourados, v. 5, n. 13, p. 21-41, maio/ago. 2015.

LEIJOTO, Camila Pereira. Registro do público da educação especial no censo escolar: deficiência intelectual em destaque. 2015. 71 f. Dissertação (Mestrado em Educação) - Universidade Federal de Mato Grosso do Sul, Corumbá, 2015.

LOURENÇO FILHO, Manuel Bergström. Estatística e educação. Revista Brasileira de Estudos Pedagógicos, Rio de Janeiro, v. 11, n. 31, p. 60-73, nov./dez. 1947. 
LOURENÇO FILHO, Manuel Bergström. Antecedentes e primeiros tempos do Inep. Revista Brasileira de Estudos Pedagógicos, Rio de Janeiro, v. 42, n. 95, p. 8-17, jul./set. 1964.

MARTINS, Susana da Cruz; MAURITTI, Rosário; COSTA, António Firmino da. Acesso a bases de microdados: aplicações e impactos na pesquisa em ciências sociais. Mediações, Londrina, PR, v. 18, n. 1, p. 66-82, jan.jjun. 2013.

MELETTI, Silvia Márcia Ferreira; BUENO, José Geraldo Silveira. Escolarização de alunos com deficiência: uma análise dos indicadores sociais no Brasil (1997-2006). In: REUNIÃO ANUAL DA ANPED: Educação no Brasil: o balanço de uma década, 33., 2010, Caxambu. Anais... Caxambu: ANPEd, 2010. v. 1, p. 1-17.

MELETTI, Silvia Márcia Ferreira; BUENO, José Geraldo Silveira (Org.). Políticas públicas, escolarização de alunos com deficiência e a pesquisa educacional. 1. ed. Araraquara, SP: Junqueira \& Marin, 2013.

MELETTI, Silvia Márcia Ferreira; RIBEIRO, Karen. Indicadores educacionais sobre a educação especial no Brasil. Cadernos CEDES, Campinas, SP, v. 34, n. 93, p. 175-189, maio 2014.

MELO, Hilce Aguiar. O acesso curricular para alunos com deficiência intelectual na rede regular de ensino: a prática pedagógica na sala de recursos como eixo para análise. 2008. 171 f. Dissertação (Mestrado em Educação) - Universidade Federal do Maranhão, São Luís, 2008.

MENDES, Enicéia. Deficiência mental: a construção científica de um conceito e a realidade educacional. 1995. Tese (Doutorado em Psicologia) Universidade de São Paulo, São Paulo, 1995.

MICHELS, Maria Helena; GARCIA, Rosalba Maria Cardoso. A organização curricular na articulação entre serviço especializado e classe comum: um modelo inclusivo? In: KASSAR, Mônica de Carvalho Magalhães (Org.). Diálogos com a diversidade: desafios da formação de educadores na contemporaneidade. Campinas, SP: Mercado das Letras, 2010. p. 211-231.

NÚCLEO DE ESTUDOS DE POLÍTICAS PÚBLICAS. Brasil 1986: relatório sobre a situação social do país. Campinas, SP: Unicamp/NEPP, 1988.

PASCHOALICK, Wanda. Análise do processo de encaminhamento de crianças das classes especiais para deficientes mentais, desenvolvido nas escolas de $1^{\circ}$ grau da delegacia de ensino de Marilia. 1981. Dissertação (Mestrado em Educação) Pontifícia Universidade Católica de São Paulo, São Paulo, 1981.

PEREIRA, Carlos Alberto Bragança; MAZZON, José Afonso; ROSENBERG, Lia. Censo Escolar: controle de qualidade. Revista Brasileira de Estudos Pedagógicos, Brasília, DF, v. 79, n. 191, p. 74-82, jan./abr. 1998.

PLETSCH, Márcia Denise. A escolarização do aluno com deficiência intelectual... apesar do diagnóstico. In: MELETTI, Silvia Márcia Ferreira; KASSAR, Mônica de Carvalho Magalhães (Org.). Escolarização de alunos com deficiências: desafios e possibilidades. Campinas, SP: Mercado de Letras, 2013. 
POPKEWITZ, Tom; LINDBLAD, Sverker. Estatísticas educacionais como um sistema de razão: relações entre governo da educação e inclusão e exclusão sociais. Educação \& Sociedade, Campinas, SP, v. 22, n. 75, p. 111-148, ago. 2001.

PRIETO, Rosângela Gavioli. Políticas de inclusão escolar no Brasil: sobre novos/velhos significados para a educação especial. In: MENDES, Enicéia; ALMEIDA, Maria Amélia (Org.). Das margens ao centro: perspectivas para as políticas e práticas educacionais no contexto da educação especial inclusiva. Araraquara, SP: Junqueira \& Marin, 2010. p. 61-78.

REBELO, Andressa Santos. Os impactos da política de atendimento educacional especializado: análise dos indicadores educacionais de matrículas de alunos com deficiência. 2012. Dissertação (Mestrado em Educação) - Universidade Federal de Mato Grosso do Sul, Corumbá, 2012.

ROSEMBERG, Fúlvia. A avaliação de programas, indicadores e projetos em educação infantil. Revista Brasileira de Educação, Rio de Janeiro, n. 16, p. 19-26, jan./abr. 2001.

ROSEMBERG, Fúlvia. Políticas de educação infantil e avaliação. Cadernos de Pesquisa, São Paulo, v. 43, n. 148, p. 44-75, jan./abr. 2013.

SANTOS FILHO, José Camilo; GAMBOA, Silvio Sánchez (Org.). Pesquisa educacional: quantidade-qualidade. 7. ed. São Paulo: Cortez, 2009.

SASS, Odair. Sobre os conceitos de censo e amostragem em educação no Brasil. Estatística e Sociedade, Porto Alegre, v. 2, p. 128-141, nov. 2012.

SASS, Odair. Estatística e estatísticas escolares no Brasil: a emergência dos serviços públicos de Estatística, sob a óptica de Rui Barbosa. In: MELETTI, Silvia Márcia Ferreira; BUENO, José Geraldo Silveira (Org.). Políticas públicas, escolarização de alunos com deficiência e a pesquisa educacional. 1. ed. Araraquara, SP: Junqueira \& Marin, 2013. p. 39-52.

SCHRADER, Achim. Métodos de pesquisa social empírica e indicadores sociais. Porto Alegre: Editora UFRGS, 2002.

SHIROMA, Eneida Oto; EVANGELISTA, Olinda. Avaliação e responsabilização pelos resultados: atualizações nas formas de gestão de professores. Perspectiva, Florianópolis, v. 29, n. 1, p. 127-160, out. 2011.

SOUZA, Celina. Estado da arte da pesquisa em políticas públicas. In: HOCHMAN, Gilberto; ARRETCHE, Marta; MARQUES, Eduardo (Org.). Políticas públicas no Brasil. Rio de Janeiro: Fiocruz, 2007. p. 65-86.

VIDAL, Eloisa Maia; VIEIRA, Sofia Lerche. Gestão educacional e resultados no Ideb: um estudo de caso em dez municípios cearenses. Estudos em Avaliação Educacional, São Paulo, v. 22, n. 50, p. 419-434, set./dez. 2011. 
ANDRESSA SANTOS REBELO

Professora Adjunta da Universidade Federal de Mato Grosso

do Sul (UFMS), Corumbá, Mato Grosso do Sul

andressarbl@gmail.com

http://orcid.org/0000-0003-1873-5622

MÔNICA DE CARVALHO MAGALHÃES KASSAR

Professora Associada da Universidade Federal de Mato

Grosso do Sul (UFMS), Corumbá, Mato Grosso do Sul

monica.kassar@gmail.com 